\title{
THE FUNCTION OF PLANTATION FORESTRY IN LANDSCAPE CONNECTIVITY
}

\author{
CABARgA-VARONA, A. ${ }^{1}-$ ARroYo, N. L. ${ }^{2}-$ NOGUÉS, S. ${ }^{1 *}$ \\ ${ }^{1}$ GEURBAN Research Group, Dpt. of Geography, Urban and Regional Planning, School of \\ Civil Engineering, University of Cantabria, Av. Los Castros, 44, 39005 Santander, Spain. \\ (phone: +34-942-201780; fax: +34-942-201703)
}

${ }^{2}$ Leonardo Torres Quevedo Foundation, University of Cantabria, Av. Los Castros, 44, 39005 Santander, Spain.

*Corresponding author

e-mail: soledad.nogues@unican.es

(Received $17^{\text {th }}$ Mar 2015; accepted 21 ${ }^{\text {st }}$ Mar 2016)

\begin{abstract}
Plantation forestry has been widely used for industrial purposes, creating vast extensions of culture forests. Although these plantations have a primary economic goal, they may indirectly serve other functions, such as landscape connectivity. Eucalypts are among the main plantation species used worldwide. In those areas in which they are not native, eucalyptus have been regarded as pernicious species for autochthonous forest and forest dwelling fauna. However, they may enhance connectivity between natural forest patches, thus favouring faunal dispersal. In Cantabria (Spain), Eucalyptus globulus were extensively planted in deforested areas mainly occupied by bushes and meadows. Here, we examine whether their massive introduction has modified landscape connectivity in the region. We used two indices based on graph theory and on the habitat availability concept (Integral Index of Connectivity and Probability of Connectivity), and applied them to the current forest network. Our results show how eucalyptus afforestation, principally based on temporary woodlands, has not improved forest connectivity in Cantabria significantly, though in the coast some of the new plantation areas may be locally important. Specific management actions targeted at these particularly relevant patches may enhance faunal dispersal and thus maintain biodiversity by reducing the fragmentation of these highly humanized areas.
\end{abstract}

Keywords: Eucalyptus globulus, afforestation, graph-theory, fragmentation, forest management

\section{Introduction}

Landscape connectivity is a key factor for the conservation of forest-dwelling species, since it guarantees genetic exchange among populations as well as increasing habitat availability (Taylor et al., 1993; Pascual-Hortal and Saura, 2006, 2008; Saura et al., 2011a; Blazquez-Cabrera et al., 2014). Deforestation reduces and fragments forest habitats, and consequently produces a loss of connectivity and increased habitat fragmentation (sensu Fahrig, 2003), which is a common spatial pattern in humanmodified landscapes (Fischer and Lindenmayer, 2007; Harper et al., 2007).

The various industrial processes that use timber as a raw material have been, together with livestock and agriculture, a major factor in the deforestation of extensive areas worldwide (Anderson, 1990). Yet, logging has not always meant a loss of forest area, since timber demand has often extended forested areas by planting fast-growing species in areas which were already devoid of any tree cover. Indeed, in some countries during the last decades, the expansion of plantation forestry has reduced the rate of natural deforestation (Heilmayr, 2014). Despite this, modern forestry has radically altered the overall dynamics and structure of most forest ecosystems (Lindenmayer et al., 1999; 
Bergsten et al., 2013), especially when the establishment of forest plantations has involved the removal of native forest cover and its replacement by exotic species (Zurita et al., 2006; Aubin et al., 2008; Calviño-Cancela et al., 2012; Nahuelhual et al., 2012). More recently, plantations have occupied former traditional agricultural landscapes or mosaics, which are also valuable habitats for some species (Bennett et al., 2006; Santos et al., 2013).

It is generally accepted that natural forests offer better quality habitats for native forest species than plantation ones (Fabiao et al., 2002; Brockerhoff et al., 2008; Bauhaus et al., 2009; Calviño-Cancela and Rubido-Bará, 2013), since species are normally better adapted to the conditions of the native habitat in which they have evolved (Calviño-Cancela et al., 2012). Moreover, the rapid creation of plantations with characteristic intensive culture structures, added to their temporary nature implies ecological conditions that do not usually fulfill the habitat requirements of native fauna. For instance, short rotations in plantation forest can result in that vulnerable or more threatened species that require more stable forest networks may not be able to survive (Brockerhoff et al., 2003), or may be more easily predated upon than in habitats offering more permanent shelter conditions (Sanchez-Oliver et al., 2014). Despite this, plantations (even of exotic species), have been found to offer refuge and food for local faunas (Tellería and Galarza, 1990, 1991), and may even enhance the natural restoration of native forests when they acquire "old-growth" conditions (Humphrey, 2005) or when the physical and biological conditions of the native forest are modified positively (e.g. Geldenhuys, 1997).

These positive interactions especially occur when plantations are integrated in a landscape mosaic, together with the remaining natural forest network, thus benefitting both plantation purposes and the ecological services provided by the forest network (Brockerhoff et al., 2013). Moreover, this mosaic distribution can be useful for wildlife movements, by potentially expanding the availability of stepping-stones and movement paths in a given network (e.g. Nogués and Cabarga-Varona, 2014). Thus, plantation patches can enhance landscape connectivity acting as catalyzers of species movements between natural forest remnants (Hartley, 2002; Brockerhoff et al., 2008 and references therein), especially in those areas where natural forests are scarce, such as in densely urbanized areas (Kramer-Schadt et al., 2004). In this sense, patches which are more important from a connectivity perspective may need specific management practices such as protection figures or renaturalization measures (Nogués and Cabarga-Varona, 2014), so that the ecological services they provide are maintained.

The extent to which these patches may be utilized by the existing fauna will depend, among other factors, on their dispersal capabilities and the specific obstacles or permeability posed by the particular landscapes the patches are connecting (Fu et al., 2010; Gurrutxaga et al., 2011; Decout et al., 2012; Liu et al., 2014a; Hernández et al., 2015). In this sense, the threshold distance or the distance a species can cover in its dispersal movements is fundamental for species colonization at large scales, since it allows species migration and establishment in new habitat areas (Gil-Tena et al., 2013).

Eucalypt (Eucalyptus globulus) plantations were massively introduced in Cantabria (Northern Spain) in the late 40's and have since then expanded anthropically throughout the region due to increases in industrial activities. We analysed the role of these forest masses in landscape connectivity in Cantabria using two indicators based on graph theory. Specifically, we wanted to know whether these plantations have improved landscape connectivity in the regional forest network. We used a multi-species approach 
for terrestrial forest-dwelling species (see e.g. García-Feced et al., 2011) using various threshold distances.

\section{Material and methods}

\section{Study area}

Cantabria is a ca. $5,300 \mathrm{~km}^{2}$ region located in the north of Spain (Fig. 1). Our choice of this region was not arbitrary, but motivated by its particular natural features, i.e.: its administrative borders present a fairly accurate adjustment to physical boundaries, since it limits to the north with the Atlantic Ocean, to the south with the Cantabrian Mountains, and to the east and west with the Deva and Agüera river basins. The mountainous relief and proximity to the sea determine a mild and humid Atlantic climate, with abundant orographic rainfall, where the predominant landscape should be temperate forests (composed principally by deciduous species such as Quercus robur and Fagus sylvatica, and evergreen ones as Quercus ilex). These natural forests are mainly located inland, and inhabited by some endangered faunal species such as the Iberian wolf (Canis lupus signatus), the brown bear (Ursus arctos arctos), or the Cantabrian capercaillie (Tetrao urogallus cantabricus), among others. Intensive forestry (almost entirely composed of E. globulus) and meadows characterize the landscape in coastal areas, which are also more densely urbanized and where the bulk of the road network lies.

Ancient forests disappeared due to various activities which took place from the modern age until the 19th century: ship construction, cannon and conventional foundries, mining, etc. Eucalyptus plantations began to be introduced during the second half of the 19th century (initially for mine lining and construction), especially in the vicinity of Torrelavega (Barreda, 1961). At this point, natural forests were already considerably reduced, especially in the coastal plain, and the dominant landscapes were rural areas consisting of farmlands and pastures, villages, and a deforested tree cover, restricted to a few small natural forest patches. The massive introduction of eucalyptus in the region was triggered by the operation of SNIACE (Spanish acronym for National Society of Industries for Applications of Spanish Cellulose), in 1944 (Nogués, 1987). The location of the cellulose plant in Torrelavega was mainly due to the favourable physical characteristics of the county of Torrelavega (high land availability, nearness to a river, and excellent communications). More importantly, the company was granted the possibility of replanting vast extensions with eucalypts through extensive land concessions. These plantations were mainly located between 0 and 350 metres of altitude, i.e.: principally along the coastal plain, and within the altitudinal limit of the eucalypts (MMA, 1966). Thus, the installation of the factory provoked a rapid increase in eucalypt plantation surface (annual 10.17\% increase between 1953 and 1966, or from ca. 15,000 to 34,836 ha) (Barreda, 1961; Estadística Forestal de España, 1966), coinciding with an economic prosperity period which ended abruptly with the 1970's economic crisis. From 1960 to 2006, the annual increase rate in eucalyptus surface dropped to $1.04 \%$, and by 2006 eucalypts occupied 49,369 ha. Nowadays eucalypts dominate the coastal landscape in Cantabria, where they represent the main forest cover (Fig. 1). 


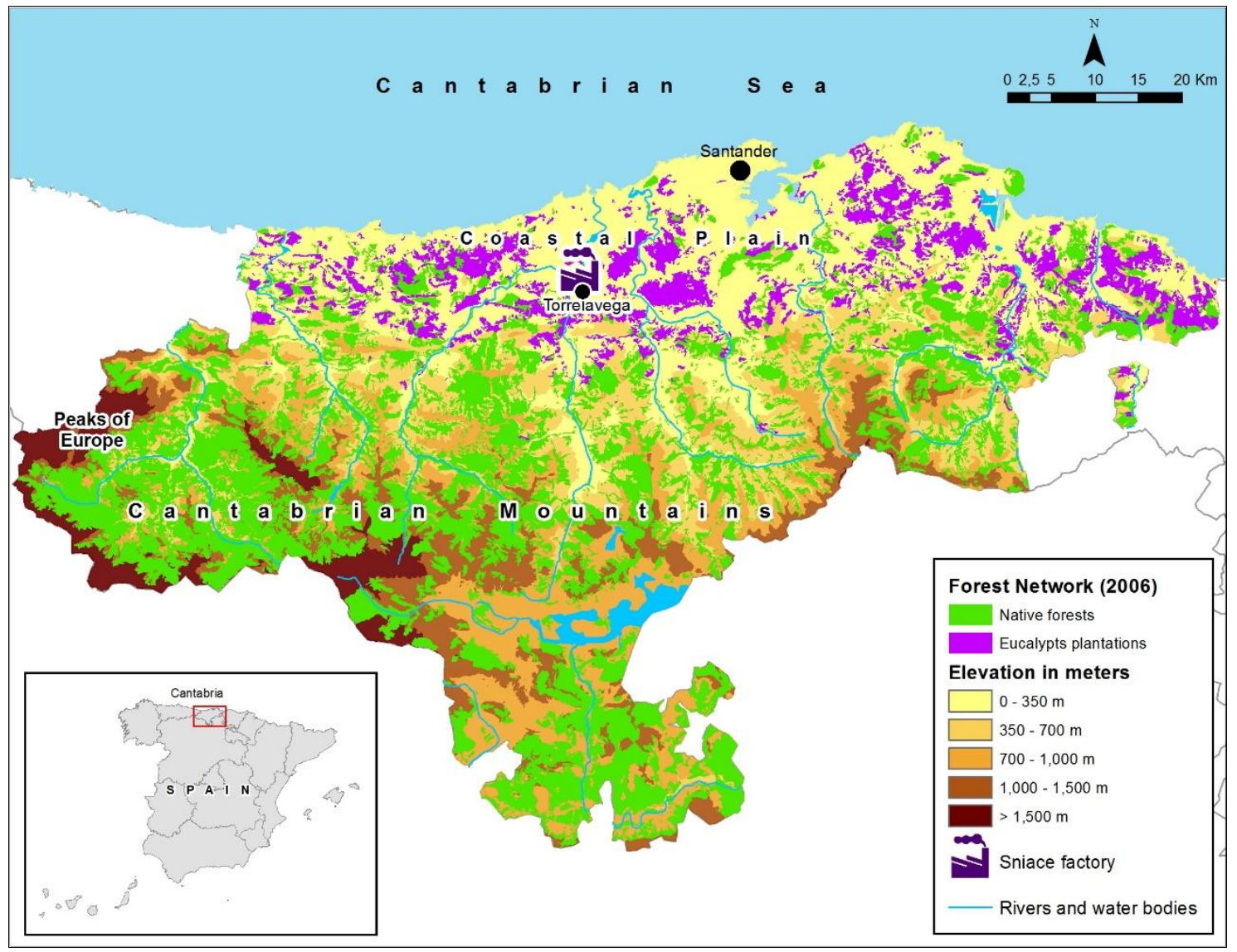

Figure 1. Topography and forest cover (Spanish Forest Map) in Cantabria in 2006

\section{Data preparation}

Forest cover data was based on availability and adequacy of the Spanish Forest Maps series to the aims of the study. We used the most recent (MMA, 2006) version of the Spanish Forest Map (1:50,000) as a cartographical base for our analyses. Given the complexity of the landscape network in our study area (i.e.: dense Atlantic forest cover, with numerous nodes and patches subdivided into multi-species polygons), and to avoid computational bottlenecks, we simplified the forest network by considering only those patches larger than 20 ha. Further, we aggregated adjacent patches (see e.g. BlazquezCabrera et al., 2014) and defined two types of forest patches: those in which native species accounted for more than $50 \%$ of the total patch cover (hereafter referred to as "natural"), and those in which eucalyptus predominated ( $>50 \%$; hereafter referred to as "eucalyptus" patches). In this way, we reduced the number of patches from 1,130 to 519. This methodological adjustment resulted in networks with synthetic patches (natural vs. eucalyptus), and thus with a simplified structure and reduced species richness compared to the real ones. By considering only those patches $\geq 20$ ha, we also minimized the possible effect of regular sequential forest logging due to eucalypt exploitation on patch availability, since usually smaller patches within these 20 ha are cut.

\section{Landscape connectivity calculation}

The role of plantations in landscape connectivity can be assessed using various connectivity metrics. Among them, those based in graph theory have been identified as 
the most adequate when analyzing connectivity related conservation problems at relatively large scales. These measures have modest data requirements and allow analyzing the potential functional connectivity for the fauna with reasonable detail (Calabrese and Fagan, 2004).

We used two complementary indices, the Integral Index of Connectivity (IIC) and the Probability of Connectivity (PC) index (Saura and Torné, 2009; García-Feced et al., 2011; Saura et al., 2011a; Gil-Tena et al., 2013). The integral index of connectivity uses a binary connection model of connectivity, while PC is probabilistic based, i.e.: it takes into account probabilities of direct dispersal between two habitat patches (Bodin and Saura, 2010). Thus, while the binary connection model considers any two patches as either connected or not (with no intermediate modulation, i.e.: graphs with unweighted links), the probabilistic model allows capturing the probability of direct dispersal between nodes as a decreasing exponential function of inter-patch distance (graphs with weighted links) (Saura and Pascual-Hortal, 2007a). Both indices integrate habitat patch area (or other patch attributes) and connections between different patches in a single metric (Pascual-Hortal and Saura, 2006). Therefore, the indices are based on two complementary concepts (Rubio et al., 2012), themselves useful for landscape connectivity analysis: graph theory, which allows modeling the relationships among nodes of a network (Urban and Keitt, 2001; Galpern et al., 2011), and the habitat availability concept, which considers a patch as a space where there is connectivity, implying that the larger the patch, the larger the connected area (Saura and PascualHortal, 2007b; Pascual-Hortal and Saura, 2008).

The IIC and PC indices are computed following Saura and Pascual-Hortal (2007b) and Pascual-Hortal and Saura (2008), as:

$$
\begin{array}{r}
I I C=\frac{\sum_{i=1}^{n} \sum_{j=1}^{n} \frac{a_{i} \cdot a_{j}}{1+n l_{i j}}}{A_{L}^{2}} \\
P C=\frac{\sum_{i=1}^{n} \sum_{j=1}^{n} a_{i} a_{j} p_{i j}^{*}}{A_{L}^{2}}
\end{array}
$$

Where $a_{i}$ and $a_{j}$ are the areas of patches $i$ and $j$, respectively, $A_{L}$ is the total landscape area (comprising both habitat and non-habitat patches), defined as the maximum product probability of all possible paths between patches $\mathrm{i}$ and $\mathrm{j} ; \mathrm{nl}_{\mathrm{ij}}$ (IIC) is the number of routes in the shortest path (least-cost paths) between nodes $i$ and $j$, and $p_{i j}(P C)$ is the direct dispersal probability which includes the least-cost distances between each two patches at the different threshold distances established. Following Fu et al. (2010), we considered the same probability of dispersals between any two patches (i.e.: 0.5 for all threshold distances see below for more details on threshold distance).

Least-cost distances were calculated based on a friction matrix which was built according to the 2006 Spanish Forest Map (MMA, 2006). This friction layer or landscape matrix is a raster map where each cell represents the relative difficulty or cost of moving through that cell for a given species (Adriaensen, 2003). Least cost distances have been considered a better predictor of animal movement than Euclidean ones since they reproduce animal movements more realistically (Fu et al., 2010; Decout et al., 
2012; Szabó et al., 2012; Ziólkowska et al., 2014). Due to processing capability limitations and considering computing time, we composed the landscape matrix at a cell size of 100 meters.

We proposed resistance values, based on our knowledge of the study area and values previously tested in the literature (e.g.: Fu et al., 2010; Gurrutxaga et al., 2011; Laita et al., 2011; Decout et al., 2012; Saura et al., 2011a; Clauzel et al., 2014). The lowest resistance values (0) were assigned to forest patches, which represent the node network in route calculation since they may function as a habitat or stepping stone (Table 1). Despite the fact that sometimes plantation forests pose greater resistance for species movements than native ones, considering the scale of our study and the overlapping of natural and planted species in several of our patches, we gave the same homogenous friction value to the whole forest network. In this way, we assumed homogeneity in the landscape connectivity role played by natural and plantation forests, assigning the same level of stepping-stone functionality to all types of patch, regardless of their composition. We also assigned low resistance values to bushes, given their presumable role as stepping-stone areas; and to agriculture land and meadows, which as an open field, also offer low resistance to dispersal. These landscape types are also often devoid of human-associated obstacles such as those appearing in urban areas. We assigned high resistance values to urban areas and water bodies (Table 1), to ensure that least-cost paths did not cross these barriers unless no other possibility of movement existed (see e.g. Decout et al., 2012; Ziólkowska et al., 2012). Finally, we added additional slope resistances to all cells, giving extra high values to those areas with very high slope conditions (Table 1). We edited all the land uses/covers in vector format and then converted them into a raster grid with 100 meters of cell size (see e.g. Ziólkowska et al., 2012). Management of the spatial data was performed using ArcGis 10.0 GIS software (ESRI ${ }^{\circledR}$ ArcMap $\left.^{\mathrm{TM}} 10.0\right)$. Least cost paths were obtained using the ArcGis extension Linkage Mapper 1.0.2 (McRae and Kavanagh, 2011).

Table 1. Resistance values assigned to the various landscapes to construct the movement resistance matrix

\begin{tabular}{l|l}
\hline Land cover / use & Friction \\
\hline Forest & 0 \\
Bushes & 4 \\
Agriculture-meadows & 8 \\
Water bodies & 100,000 \\
Artificial (urban areas, roads) & 10,000 \\
\hline Slopes-Values added to the remaining land covers & \\
\hline $0-15^{\circ}$ & 1 \\
$15-30^{\circ}$ & 2 \\
$30-45^{\circ}$ & 3 \\
$45-60^{\circ}$ & 4 \\
$>60^{\circ}$ & 250 \\
\hline
\end{tabular}

Threshold distances were established using two criteria: their adequacy to the size of the study area, which is larger than $5,000 \mathrm{~km}^{2}(100 \mathrm{~km} \mathrm{E-W}$ by $50 \mathrm{~km} \mathrm{N-S})$, and the fact that our analysis was focused on terrestrial species with varying dispersal abilities such as medium and large sized mammals (e.g.: martens (Martes martes), badgers (Meles meles), wolves (Canis lupus), or bears (Ursus arctos). We chose values previously tested by other authors for these faunal groups (Fu et al., 2010; García-Feced et al., 
2011; Gurrutxaga et al., 2011; Saura et al., 2011b; Zhao et al., 2014): 5,000, 10,000, 20,000, 30,000, 40,000, and 50,000 meters.

We based our connectivity analysis on the relative importance of the various patches found in our forest network. Following Pascual-Hortal and Saura (2006) and Saura and Pascual-Hortal (2007b), we used the simplified version of the IIC and PC indices, dIIC and $\mathrm{dPC}$, respectively, which can be interpreted as the individual importance of every single forest patch in terms of percentage variation in the total degree of connectivity, as given by the IIC and PC indices.

Thus, patch importance is given by the expressions:

$$
\begin{aligned}
& d I I C(\%)=\frac{I I C-I I C^{i}}{I I C} \cdot 100 \\
& d P C(\%)=\frac{P C-P C^{i}}{P C} \cdot 100
\end{aligned}
$$

Where IIC or PC correspond to the overall index value calculated for a specific landscape (considering all habitat patches), and IIC $^{\mathrm{i}}$ or $\mathrm{PC}^{\mathrm{i}}$ are the overall index values after removing patch $\mathrm{i}$ from the landscape. We applied the indicators to the current (2006) forest network excluding eucalypts. To evaluate the actual connectivity provided by each eucalypt patch to the natural forest network, we recalculated connectivity importance values using the "there are nodes to add" option (Conefor Sensinode 2.6, Saura and Torné, 2009). In this way, we calculated, on the one hand, the connectivity loss that the removal of each of the nodes of the original forest network (in our case, natural patches) would cause, and on the other, the connectivity improvement occurring as a result of the addition of each of the new nodes (i.e.: eucalypt patches), to the forest network. The importance of each potential (eucalypt) new node (dI) for improving landscape connectivity is calculated as:

$$
d I(\%)=100 \cdot \frac{I_{a d d}-I}{I}
$$

Where I is the overall index value when all the initially existing nodes (excluding the eucalypts, in this case) are present in the landscape and $I_{\text {add }}$ is the overall index value after the addition of each of the new eucalypt nodes to the landscape (Saura and Pascual-Hortal, 2007a).

\section{Results}

The complete (simplified) forest network was composed of 519 patches which occupied $37.57 \%\left(2,000.68 \mathrm{~km}^{2}\right)$ of the total study area $\left(5,325 \mathrm{~km}^{2}\right)$, and concentrated mainly inland. Eucalyptus patches were distributed exclusively along the coast and amounted to 151 , occupying $8.95 \%$ of the total study area $\left(476.63 \mathrm{~km}^{2}\right)$. The average eucalyptus patch size was $3.16 \mathrm{~km}^{2}$, while that of natural patches was $4.14 \mathrm{~km}^{2}$ (Figs. 2 and 3$)$. 


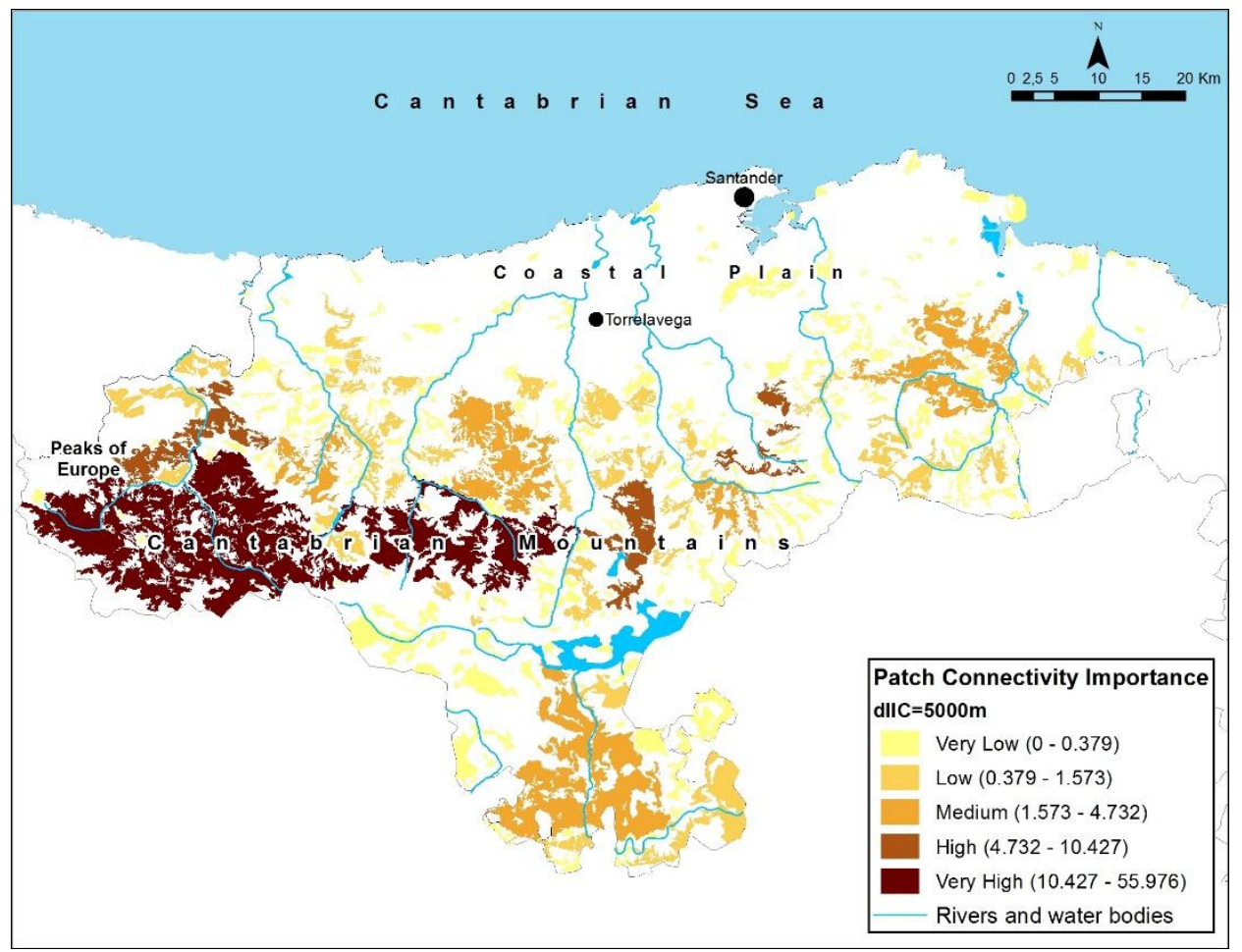

Figure 2. Patch Connectivity importance (dIIC) at d=5000m in the natural network. Patch connectivity importance categories based on natural breaks

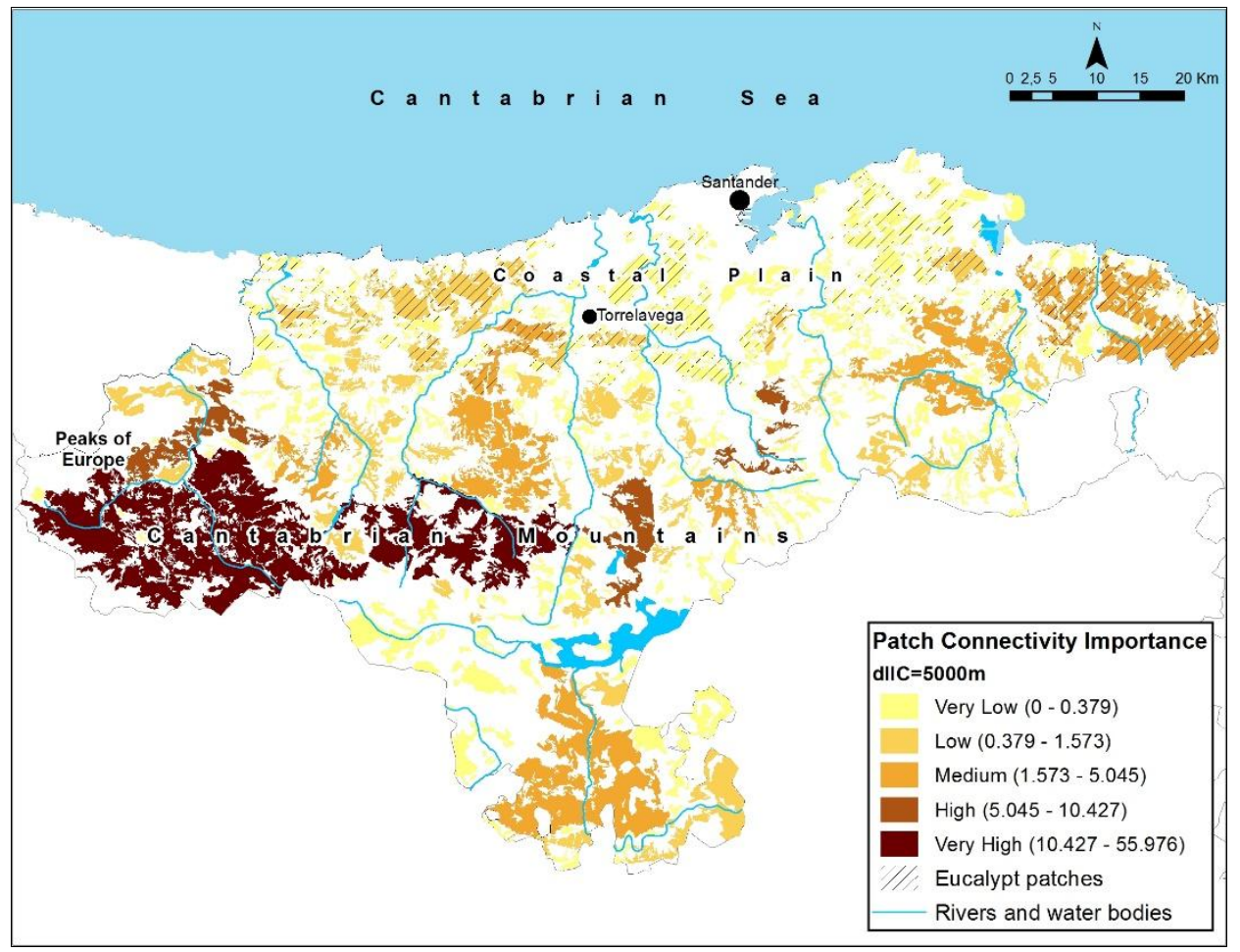

Figure 3. Patch Connectivity importance (dIIC) at $d=5000 \mathrm{~m}$ using "there are nodes to add" for eucalypt patches (striped). Patch connectivity importance categories based on natural breaks 
Results obtained with the dIIC and dPC indicators showed more or less the same trends for the whole patch network at the various threshold distances examined. The highest values in patch importance were obtained for the 5,000, 10,000 and 20,000 m distances and decreased thereafter (Table 2). The greatest relative increases in link number or connections between existing patches occurred between $\mathrm{d}=5000$ and 20,000 $\mathrm{m}$ (Table 3).

Table 2. Results of the dIIC and dPC indices for (1) the network without eucalypt patches,

(2) natural and eucalypt patches and, (3) the added eucalypt patches, at the various threshold distances examined

\begin{tabular}{l|l|r|r|r|r|r|r}
\hline \multirow{2}{*}{\multicolumn{2}{l}{}} & \multicolumn{6}{c}{ Threshold distance (m) } \\
\cline { 3 - 7 } dIIC & Max & 55.98 & 50.73 & 42.96 & 40.87 & 40.64 & 39.77 \\
\hline (1) Without eucalypt & Mean & 0.61 & 0.54 & 0.53 & 0.51 & 0.51 & 0.51 \\
patches & Sum & 225.83 & 199.20 & 193.45 & 189.51 & 188.55 & 188.04 \\
\hline (2) Natural + eucalypt & Max & 55.98 & 50.73 & 42.96 & 40.87 & 40.64 & 39.77 \\
patches & Mean & 0.48 & 0.45 & 0.46 & 0.46 & 0.46 & 0.46 \\
& Sum & 248.49 & 235.52 & 238.06 & 237.24 & 239.38 & 240.49 \\
\hline (3) Eucalypt patches & Max & 5.05 & 5.28 & 6.02 & 6.00 & 6.65 & 6.80 \\
& Mean & 0.15 & 0.24 & 0.30 & 0.32 & 0.34 & 0.35 \\
& Sum & 22.67 & 36.32 & 44.62 & 47.73 & 50.83 & 52.45 \\
\hline dPC & & $\mathbf{5 0 0 0}$ & $\mathbf{1 0 , 0 0 0}$ & $\mathbf{2 0 , 0 0 0}$ & $\mathbf{3 0 , 0 0 0}$ & $\mathbf{4 0 , 0 0 0}$ & $\mathbf{5 0 , 0 0 0}$ \\
\hline (1) Without eucalypt & Max & 55.04 & 48.62 & 43.15 & 40.80 & 39.51 & 38.69 \\
patches & Mean & 0.75 & 0.75 & 0.70 & 0.66 & 0.64 & 0.62 \\
& Sum & 276.32 & 274.44 & 257.36 & 243.85 & 234.72 & 228.35 \\
\hline (2) Natural + eucalypt & Max & 55.04 & 48.62 & 43.15 & 40.80 & 40.64 & 38.69 \\
patches & Mean & 0.57 & 0.60 & 0.59 & 0.57 & 0.46 & 0.55 \\
& Sum & 297.79 & 309.71 & 304.73 & 296.13 & 239.38 & 284.83 \\
\hline (3) Eucalypt patches & Max & 5.44 & 5.14 & 6.43 & 7.45 & 8.02 & 8.38 \\
& Mean & 0.14 & 0.23 & 0.31 & 0.35 & 0.36 & 0.37 \\
& Sum & 21.47 & 35.27 & 47.37 & 52.29 & 54.89 & 56.48 \\
\hline
\end{tabular}

There were differences in patch importance between patches of native and plantation forest (Fig. 3). The most connected landscape units were three large native patches of natural forest (Figs. 2 and 3), which accounted for less than $1 \%$ of the total number of patches. They concentrated $39.87 \%$ (dIIC) and $37.98 \%$ (dPC) of the total importance at a threshold distance of $5,000 \mathrm{~m}$, respectively, and similar values at the remaining threshold distances (Table 2). The remaining forest network (whether natural or eucalyptus dominated) was mainly composed of patches attaining low connectivity values (mean values lower than 1). Only some patches, and among them some eucalyptus ones located in the eastern and western coastal fringe, reached intermediate importance values of up to 5 or 6, at specific threshold distances (Table 2, Fig. 3).

Table 3. Number of links between nodes considering the natural and eucalypt patches

\begin{tabular}{r|r|r}
\hline $\mathbf{d}=\mathbf{m}$ & \# links natural+eucalypt patches network & \% increment \\
\hline 5000 & 1218 & - \\
10,000 & 2804 & 130.21 \\
20,000 & 8085 & 188.34 \\
30,000 & 15,669 & 93.80 \\
40,000 & 24,693 & 57.59 \\
50,000 & 34,473 & 39.61 \\
\hline
\end{tabular}


The maximum values in patch importance obtained for the natural network using the "there are nodes to add" option (i.e.: adding the eucalypt patches one by one), at all dispersal distances were equal to those obtained without eucalypts (Table 2). However, the addition of eucalypts did cause a slight decrease in mean values, as well as in the overall sum of connectivity importance (Table 2), which was higher when the plantation patches were included. Considering only the results obtained for the eucalypt patches (Table 2), they did not vary much at the various dispersal distances considered, but showed the inverse trend to that of the global network, i.e.: connectivity importance values increased the larger the distance between patches.

\section{Discussion}

Connectivity rises if for a given amount of habitat the connection status is improved, or for a given connection status, the amount of habitat increases (Fahrig, 2003; Laita et al., 2011). Since the expansion of eucalypts in Cantabria occupied previously unforested areas, indirectly at least, this should have entailed an improvement of forest connectivity in the area. However, our results indicate that the contribution of plantation forestry to landscape connectivity in Cantabria has been scarce and mainly confined to the coastal areas. Here, their importance may be even higher than that shown by our results, which were always calculated relative to the complete regional forest network. Indeed, these areas are highly fragmented due to human activities (see e.g. Gurrutxaga et al., 2011) and devoid of any large forest masses, other than the eucalypts and some very important relict patches of autochthonous vegetation,

In our study, the key connectivity providers were large natural forest patches located in the central-inland area of the region. Eucalypt patches were numerous but the majority was very small and located on the northern perimeter of the region (coastal area), which reduced their importance as connectivity providers within the whole forest network. The most important eucalypt patches were some relatively large ones connecting many routes or links, also with the isolated natural patches of high natural value close to the coast (Fig. 4). The dispersal of species inhabiting these isolated natural patches is most probably enhanced by the existence of the eucalypts (see e.g. Nogués and Cabarga-Varona, 2014).

Connectivity assessments should take into account the scale-dependent nature of habitat networks, since habitat patches can be defined at different spatial scales (from single patches to aggregations of them) (Blazquez-Cabrera et al., 2014). In our case, the severe forest network simplification conducted prior to the analyses may have had a bearing in our results, since a few very large patches agglutinated most of the connectivity importance. Thus, assessments using habitat availability and graph theory based indicators, such as dIIC and dPC, should always weigh the results obtained considering that they are highly dependent on the amount of surface which is connected, and thus in the size of the patches being evaluated. The prevalence of size dependent influences is particularly relevant in regions characterized by large and densely distributed patches, while in regions with low habitat cover the relative importance of the position of the patches within the forest network becomes more important (Rubio and Saura, 2012; Szabó et al., 2012; Zhao et al., 2014; Ziólkowska et al., 2014). Despite this, in our study the same patches were always identified as being the key connectivity providers, regardless of the landscape configurations and scales examined, and using 
two different indices (dIIC and dPC), which is in agreement with other studies in which similar patterns were found (e.g. Blazquez-Cabrera et al., 2014).

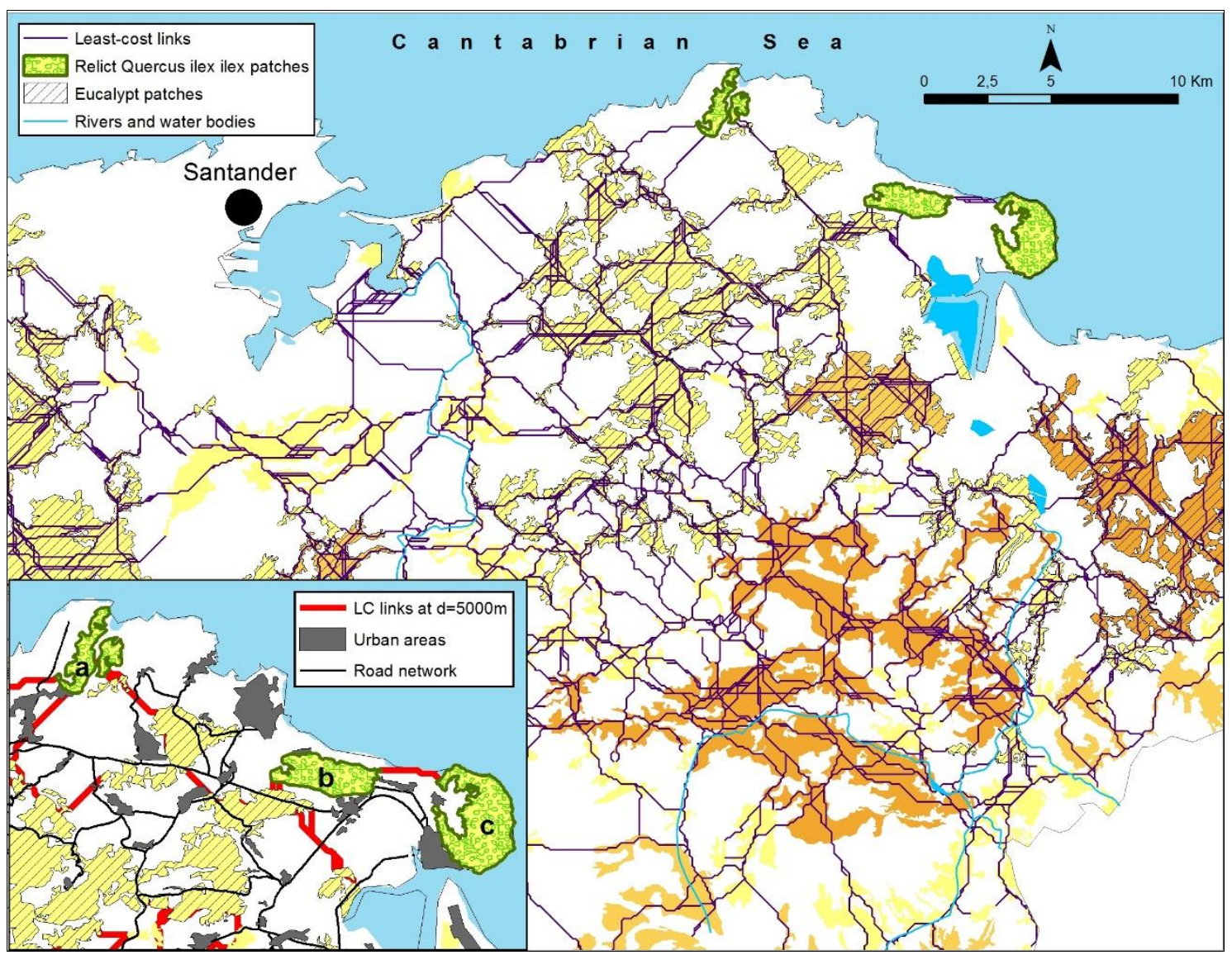

Figure 4. Detail showing the relict Quercus ilex ilex patches $(a, b, c)$ located in coastal areas and their connections (least cost links at all threshold distances) to the inland natural network through eucalypt patches. Note how for $b$ or $c$ the only possible connection route is through a single eucalypt patch. Patch Connectivity importance values and symbol categories same as in Figure 3

In our study, the highest connectivity importance results were obtained at shorter distances when examining the natural forest network. This can be related with the denser structure of the natural network, in which the availability of patches and routes among them increased with distance, thus distributing importance so that individual patches obtained lower values. Also, it implies that the natural network is more vulnerable to connectivity alterations at shorter dispersal distances, which may be especially important for poor dispersers if nearby patches disappear or are modified substantially. Conversely, eucalypt patches obtained individually the highest importance values at large threshold distances, which might be explained by the fact that eucalypt patches were sparsely distributed and some (regardless of whether they were close or at longer distances), concentrated a large number of all possible dispersal routes, thus agglutinating importance for connectivity.

All in all, our results suggest that the best dispersers might be the most benefited by the introduction of plantations, since they may be able to use the patches as stepping 
stones to move among inland natural areas. Conversely, individuals with lower dispersal ability can use eucalypt patches to move among and colonize small natural remnants existing in the coast, but they probably have problems to cross unforested areas separating them from natural forest areas in more interior locations because of their high degree of humanization (see e.g. Di Giulio et al., 2009; Fu et al., 2010; Macpherson et al., 2011; Decout et al., 2012; Yu et al., 2012; Liu et al., 2014b).

Our study identified a series of patches (both natural and eucalypt dominated) as more important in terms of connectivity, indicating that the used indices may be relevant when attempting to conduct sustainable forest management schemes, in which the ecological importance of certain patches is considered. Once identified, those plantation patches which are more important for wildlife fauna dispersal (Saura et al., 2011b), can be preserved and/or restored into natural forest or at least managed considering wildlife needs and cycles (kept uncut or avoiding cleancut practices, respecting reproduction or dispersal periods, etc.). In this sense, it would also be interesting to identify which faunal species have been more affected (both positively and negatively) by the plantations, and which use them as habitat or only as steppingstone. Further management measures could involve constructing mosaics of native and plantation patches, resulting in non-monospecific forest cultures (Carnus et al., 2006), which minimize biodiversity exchange and resilience. Eventually, many of these plantation areas could be restored into natural forest, especially in areas such as Cantabria, where the industrial activities causing the plantations are disappearing or decreasing their activity (Bowen et al., 2007; Onaindia et al., 2013; Hernández et al., 2015). These issues pose both a challenge and an opportunity for managers and practitioners intending to restore landscape connectivity in forested areas (GarcíaFeced et al., 2011), since they introduce concepts such as ecological or environmental value of plantation patches which up until now have only been considered in terms of economic benefits.

Maintaining and restoring landscape connectivity is currently a central concern in ecology and biodiversity conservation (Saura and Torné, 2009; Tambosi et al., 2014; Zhao et al., 2014). We conducted an analysis of landscape connectivity by integrating methods of graph-based habitat availability (reachability) metrics and least-cost path matrices (Rubio and Saura, 2012; Ziólkowska et al., 2012), that allow the identification of key nodes providing connectivity. This is a valuable contribution for forest management tools, especially when the alterations of human disturbances to specific patches rendering some unsuitable, or reducing their ability to provide appropriate habitats for wildlife, are considered (Reza et al., 2013). In this way, forests managers and land planners can identify where management and conservation efforts should be concentrated and prioritized.

\section{REFERENCES}

[1] Adriaensen, F., Chardon, J.P., De Blust, G., Swinnen, E., Villalba, S., Gulinck, H., Matthysen, E. (2003): The application of 'least-cost' modeling as a functional landscape model. - Landscape and Urban Planning 64: 233-247.

[2] Anderson, A.B. (1990): Smokestacks in the rainforest: industrial development and deforestation in the Amazon basin. - World Development 18: 1191-1205. 
[3] Aubin, I., Messier, C., Bouchard, A. (2008): Can plantations develop understory biological and physical attributes of naturally regenerated forests?. - Biological Conservation 141: 2461-2476.

[4] Barreda, F. (1961): Los primeros eucaliptos plantados en Santander. - Revista Altamira: 1-3.

[5] Bauhus, J., Puettmann, K., Messier, C. (2009): Silviculture for old-growth attributes. Forest Ecology and Management 258: 525-537.

[6] Bennett, A.F., Radford, J.Q., Haslem, A. (2006): Properties of land mosaics: Implications for nature conservation in agricultural environments. - Biological Conservation 133: 250264.

[7] Bergsten, A., Bodin, Ö., Ecke, F. (2013): Protected areas in a landscape dominated by logging - A connectivity competition-colonization tradeoffs. - Biological Conservation 160: 279-288.

[8] Blazquez-Cabrera, S., Bodin, Ö., Saura, S. (2014): Indicators of the impacts of habitat loss on connectivity and related conservation priorities: Do they change when habitat patches are defined at different scales?. - Ecological Indicators 45: 704-716.

[9] Bodin, Ö., Saura, S. (2010): Ranking individual habitat patches as connectivity providers: integrating network analysis and patch removal experiments. - Ecological Modelling 221: 2393-2405.

[10] Bowen, M.E., McAlpine, C.A., House, A.P.N., Smith, G.C. (2007): Regrowth forests on abandoned agricultural land: A review of their habitat values for recovering forest fauna. - Biological Conservation 140: 273-296.

[11] Brockerhoff, E.G., Ecroyd, C.E., Leckie, A.C., Kimberley, M.O. (2003): Diversity and sucession of adventive and indigenous vascular understory plants in Pinus radiata plantation forest in New Zealand. - Forest Ecology and Management 185: 307-326.

[12] Brockerhoff, E.G., Jactel, H., Parrotta, J.A., Ferraz, S.F.B. (2013): Role of eucalypt and other planted forests in biodiversity conservation and the provision of biodiversity-related ecosystem services. Forest Ecology and Management 301: 43-50.

[13] Brockerhoff, E.G., Jactel, H., Parrotta, J.A., Quine, C.P., Sayer, J. (2008): Plantation forests and biodiversity: oxymoron or opportunity? - Biodiversity and Conservation 17: 925-951.

[14] Calabrese, J.M., Fagan, W.F. (2004): A comparison-shopper's guide to connectivity metrics. - Frontiers in the Ecology and the Environment 10: 529-536.

[15] Calviño-Cancela, M., Rubido-Bará, M. (2013): Invasive potential of Eucalyptus globulus: Seed dispersal, seedling recruitment and survival in habitats surrounding plantations. Forest Ecology and Management 305: 129-137.

[16] Calviño-Cancela, M., Rubido-Bará, M., van Etten, E.J.B. (2012): Do eucalypt plantations provide habitat for native forest biodiversity? - Forest Ecology and Management 270: 153-162.

[17] Carnus, J-M., Parrotta, J., Brockerhoff, E.G., Arbez, M., Jactel, H., Kremer, A., Lamb, D., O'Hara, K., Walters, B. (2006): Planted forest and biodiversity. - Journal of Forestry 104: 65-77.

[18] Clauzel, C., Bannwarth, C., Foltete, J.C. (2014): Integrating regional-scale connectivity in habitat restoration: An application for amphibian conservation in eastern France. - Journal for Nature Conservation, Article in press.

[19] Decout, S., Manel, S., Miaud, C., Luque, S. (2012): Integrative approach for landscapebased graph connectivity analysis: a case study with the common frog (Rana temporaria) in human-dominated landscapes. - Landscape Ecology 27: 267-279.

[20] Di Giulio, M., Holderegger, R., Tobias, S. (2009): Effects of habitat and landscape fragmentation on human and biodiversity in densely populated landscapes. - Journal of Environmental Management 90: 2959-2968.

[21] Estadística Forestal de España (1966): Primer Inventario Nacional. - Ministerio de Agricultura, Dirección General de Montes. 
[22] Fabiao, A., Martins, M.C., Cerveira, C., Santos, C., Lousa, M., Madeira, M., Correia, A. (2002): Influence of soil and organic residue management on biomass and biodiversity of understory vegetation in a Eucalyptus globulus Labill plantation. - Forest Ecology and Management 171: 87-100.

[23] Fahrig, L. (2003): Effects of habitat fragmentation on biodiversity. - Annual Review of Ecology, Evolution, and Systematics 34: 487-515.

[24] Fischer, J., Lindenmayer, D.B. (2007): Landscape modification and habitat fragmentation: a synthesis. - Global Ecology and Biogeography 16: 265-280.

[25] Fu, W., Liu, S., Degloria, S.D., Dong, S., Beazley, R. (2010): Characterizing the "fragmentation-barrier" effect of road networks on landscape connectivity: A case study in Xishuangbanna, Southwest China. - Landscape and Urban Planning 95: 122-129.

[26] Galpern, P., Manseau, M., Fall, A. (2011): Patch-based graphs of landscape connectivity: A guide to construction, analysis and application for conservation. - Biological Conservation 144: 44-55.

[27] García-Feced, C., Saura, S., Elena-Rosselló, R. (2011): Improving landscape connectivity in forest districts: A two-stage process for prioritizing agricultural patches for reforestation. - Forest Ecology and Management 261: 154-161.

[28] García-Martino, F. (1862): Bosquejo dasográfico de la provincia de Santander 1:250.000. - Junta General de Estadística. Madrid, España.

[29] Geldenhuys, C.J. (1997): Native forest regeneration in pine and eucalypt plantations in Northern Province, South Africa. - Forest Ecology and Management 99: 101-115.

[30] Gil-Tena, A., Brotons, L., Fortin, M.J., Burel, F., Saura, S. (2013): Assessing the role of landscape connectivity in recent woodpecker range expansion in Mediterranean Europe: forest management implications. - European Journal of Forest Research 132: 181-194.

[31] Gurrutxaga, M., Rubio, L., Saura, S. (2011): Key connectors in protected forest area networks and the impact of highways: A transnational case study from the Cantabrian Range to the Western Alps (SW Europe). - Landscape and Urban Planning 101: 310-320.

[32] Harper, G.J., Steininger, M.K., Tucker, C.J., Juhn, D., Hawkins, F. (2007): Fifty years of deforestation and forest fragmentation in Madagascar. - Environmental Conservation 34: 325-333.

[33] Hartley, M.J. (2002): Rationale and methods for conserving biodiversity in plantation forests. - Forest Ecology and Management 155: 81-95.

[34] Heilmayr, R. (2014): Conservation through intensification? The effects of plantations on natural forests. - Ecological Economics 105: 204-210.

[35] Hernández, A., Miranda, M., Arellano, E.C., Saura, S., Ovalle, C. (2015): Landscape dynamics and their effect on the functional connectivity of a Mediterranean landscape in Chile. - Ecological Indicators 48: 198-206.

[36] Humphrey, J.W. (2005): Benefits to biodiversity from developing old-growth conditions in British upland spruce plantations: a review and recommendation. - Forestry 78: 33-53.

[37] Kramer-Schadt, S., Revilla, E., Wiegand, T., Breitenmoser, U. (2004): Fragmented landscapes, road mortality and patch connectivity: modeling influences on the dispersal of Eurasian lynx. - Journal of Applied Ecology 41: 711-723.

[38] Laita, A., Kotiaho, J.S., Mönkkönen, M. (2011): Graph-theoretic connectivity measures: what do they tell us about connectivity?. - Landscape Ecology 26: 951-967.

[39] Lindenmayer, D.B., Cunningham, R.B., Pope, M.L. (1999): A large-scale "experiment" to examine the effects of landscape context and habitat fragmentation on mammals. Biological Conservation 88: 387-403.

[40] Liu, S., Deng, L., Dong, S., Zhao, Q., Yang, J., Wang, C. (2014a): Landscape connectivity dynamics based on network analysis in the Xishuangbanna Nature Reserve, China. - Acta Oecologica 55: 66-77.

[41] Liu, S., Dong, Y., Deng, L., Liu, Q., Zhao, H., Dong, S. (2014b): Forest fragmentation and landscape connectivity change associated with road network extension and city expansion: A case study in the Lancang River Valley. - Ecological Indicators 36: 160-168. 
[42] Macpherson, D., Macpherson, J.L., Morris, P. (2011): Rural roads as barriers to the movements of small mammals. - Applied Ecology and Environmental Research 9 (2): 167-180.

[43] McRae, B.H., Kavanagh, D.M. (2011): Linkage Mapper Connectivity Analysis Software. The Nature Conservancy, Seattle WA. Available at: http://www.circuitscape.org/linkagemapper.

[44] MMA (1966): Mapa Forestal de España 1:400.000. - Ministerio de Agricultura. Madrid.

[45] MMA (2006): Mapa Forestal de España 1:50.000. - Ministerio de Medio Ambiente, Organismo Autónomo de Parques Nacionales. Madrid, España.

[46] Nahuelhual, L., Carmona, A., Lara, A., Echeverría, C., González, M.E. (2012): Landcover change to forest plantations: Proximate causes and implications from the landscape in south-central Chile. - Landscape and Urban Planning 107: 12-20.

[47] Nogués, S. (1987): Torrelavega: un espacio industrializado. - Ayto. de Torrelavega, $151 \mathrm{pp}$.

[48] Nogués, S., Cabarga-Varona, A. (2014): Modelling land use changes for landscape connectivity: The role of plantation forestry and highways. - Journal for Nature Conservation 22: 504-515.

[49] Onaindia, M., Ametzaga-Arregi, I., San Sebastián, M., Mitxelena, A., Rodríguez-Loinaz, G., Peña, L., Alday, J.G. (2013): Can understorey native woodland plant species regenerate under exotic pine plantations using natural succession?. - Forest Ecology and Management 308: 136-144.

[50] Pascual-Hortal, L., Saura, S. (2006): Integrating landscape connectivity in broadscale forest planning: a methodology based on graph structures and habitat availability indices. - In: Lafortezza, R., Sanesi, G. (2006): Patterns and processes in forest landscapes. Consequences of human management, 111-116.

[51] Pascual-Hortal, L., Saura, S. (2008): Integrating connectivity in broad-scale forest planning through a new graph-based habitat availability methodology: application to capercaillie (Tetrao urogallus) in Catalonia (NE Spain). - European Journal of Forest Research 127: 23-31.

[52] Reza, M.I.H., Abdullah, S.A., Nor, S.B.M., Ismail, M.H. (2013): Integrating GIS and expert judgement in a multicriteria analysis to map and develop a habitat suitability index: A case study of large mammals on the Malayan Peninsula. - Ecological Indicators 34: $149-158$.

[53] Rubio, L., Rodríguez-Freire, M., Mateo-Sánchez, M.C., Estreguil, C., Saura, S. (2012): Sustaining forest landscape connectivity under different land cover change scenarios. Forest Systems 2: 223-235.

[54] Rubio, L., Saura, S. (2012): Assessing the importance of individual habitat patches as irreplaceable connecting elements: An analysis of simulated and real landscape data. Ecological Complexity 11: 28-37.

[55] Sánchez-Oliver, J.S., Rey-Benayas, J.M., Carrascal, L.M. (2014): Local habitat and landscape influence predation of bird nests on afforested Mediterranean cropland. - Acta Oecologica 58: 35-43.

[56] Santos, T., Carbonell, R., Galarza, A., Pérez-Tris, J., Ramírez, Á., Tellería, J.L. (2013): The importance of northern Spanish farmland for wintering migratory passerines: a quantitative assessment. - Bird Conservation International 24: 1-16.

[57] Saura, S., Estreguil, C., Mouton, C., Rodríguez-Freire, M. (2011a): Network analysis to assess landscape connectivity trends: Application to European Forests (1990-2000). Ecological Indicators 11: 407-416.

[58] Saura, S., Pascual-Hortal, L. (2007a): Conefor Sensinode 2.2 User's Manual: Software for quantifying the importance of habitat patches for maintaining landscape connectivity through graphs and habitat availability indices. University of Lleida, Spain. Available at www.conefor.org. 
[59] Saura, S., Pascual-Hortal, L. (2007b): A new habitat availability index to integrate connectivity in landscape conservation planning: Comparison with existing indices and application to a case study. - Landscape and Urban Planning 83: 91-103.

[60] Saura, S., Torné, J. (2009): Conefor Sensinode 2.2: A software package for quantifying the importance of habitat patches for landscape connectivity. - Environmental Modelling \& Software 24: 135-139.

[61] Saura, S., Vogt, P., Velázquez, J., Hernando, A., Tejera, R. (2011b): Key structural forest connectors can be identified by combining landscape spatial pattern and network analyses. - Forest Ecology and Management 262: 150-160.

[62] Szabó, S., Novak, T., Elek, Z. (2012): Distance models in ecological network management: A case study of path connectivity in a grassland network. - Journal for Nature Conservation 20: 293-300.

[63] Tambosi, L.R., Martensen, A.C., Ribeiro, M.C., Metzger, J.P. (2014): A framework to optimize biodiversity restoration efforts based on habitat amount and landscape connectivity. - Restoration Ecolology 22: 169-177.

[64] Taylor, P.D., Fahrig, L., Henein, K., Merriam, G. (1993): Connectivity is a vital element of landscape structure. - Oikos 68: 571-573.

[65] Tellería, J.L., Galarza, A. (1990): Avifauna y paisaje en el norte de España: efecto de las repoblaciones con árboles exóticos. - Ardeola 37: 229-245.

[66] Tellería, J.L., Galarza, A. (1991): Avifauna invernante en un eucaliptal del norte de España. - Ardeola 38: 239-247.

[67] Urban, D., Keitt, T. (2001): Landscape connectivity: a graph-theoretic perspective. Ecology 82: 1205-1218.

[68] Yu, D., Xun, B., Shi, P., Shao, H., Liu, Y. (2012): Ecological restoration planning based on connectivity in an urban area. - Ecological Engineering 46: 24-33.

[69] Zhao, H., Liu, S., Dong, S., Su, X., Liu, Q., Deng, L. (2014): Characterizing the importance of habitat patches in maintaining landscape connectivity for Tibetan antelope in the Altun Mountain National Nature Reserve, China. - Ecological Research 29: 1065-1075.

[70] Ziólkowska, E., Ostapowicz, K., Kuemmerle, T., Perzanowski, K., Radeloff, V.C., Kozak, J. (2012): Potential habitat connectivity of European bison (Bison bonasus) in the Carpathians. - Biological Conservation 146: 188-196.

[71] Ziólkowska, E., Ostapowicz, K., Radeloff, V.C., Kuemmerle, T. (2014): Effects of different matrix representations and connectivity measures on habitat network assessments. - Landscape Ecology 29: 1551-1570.

[72] Zurita, G.A., Rey, N., Varela, D.M., Villagra, M., Bellocq, M.I. (2006): Conversion of the Atlantic Forest into native and exotic tree plantations: Effects on bird communities from the local and regional perspectives. - Forest Ecology and Management 235: 164-173. 